\title{
A Study on Maternal Mortality in Baba Raghav Das Medical College, Gorakhpur
}

\author{
${ }^{1}$ Reena Shrivastava, ${ }^{2}$ Harish C Tiwari, ${ }^{3}$ Renu Sangal
}

\begin{abstract}
Introduction: Prevention of maternal deaths is one of our foremost goals to provide safety to motherhood and to avoid loss to the family, society, and the nation. Maternal mortality ratio (MMR) of Uttar Pradesh is very high as compared to national average. Within the state, there is wide variation in MMR. The explanations and answers to these regional variations are complex. This study was planned with the objectives to explore each and every maternal death that had occurred in Baba Raghav Das Medical College in the last 4 years (2011-2014).

Materials and methods: In this study, data were collected from records of all maternal deaths that had occurred in the Department of Obstetrics and Gynecology, Baba Raghav Das Medical College, Gorakhpur from March 2011 to December 2014. Records of all maternal deaths during this period were scrutinized for socio-demographic profile, obstetric history, antenatal care history, causes of maternal mortality, time trend, geographical or regional distribution, admission and death interval, condition of patients on admission, outcome of pregnancy, and reasons for delay. Records of number of maternal deaths and live births were also collected for previous 11 years (2004-2014).
\end{abstract}

Results: Maternal mortality ratio has dropped almost six times in the last 11 years. Early age at marriage, illiteracy, poor socioeconomic status, and multiparity were found to be important determinants of maternal mortality and can act as risk factors. The pattern of causes of maternal deaths in this institute (preeclampsia) is different from that found in the community (postpartum hemorrhage). Delay in seeking care because of unawareness and illiteracy and ignorance was found to be the major contributing factor for most of the maternal deaths.

Keywords: Maternal mortality ratio, Postpartum hemorrhage, Preeclampsia.

How to cite this article: Shrivastava R, Tiwari HC, Sangal R. A Study on Maternal Mortality in Baba Raghav Das Medical College, Gorakhpur. J South Asian Feder Obst Gynae 2016;8(4):294-298.

Source of support: Nil

Conflict of interest: None

${ }^{1}$ Professor and Head, ${ }^{2}$ Lecturer, ${ }^{3}$ Associate Professor

1,3 Department of Obstetrics and Gynecology, Baba Raghav Das Medical College, Gorakhpur, Uttar Pradesh, India

${ }^{2}$ Department of Postpartum Program, Baba Raghav Das Medical College, Gorakhpur, Uttar Pradesh, India

Corresponding Author: Harish C Tiwari, Lecturer, Department of Postpartum Program, Baba Raghav Das Medical College Gorakhpur, Uttar Pradesh, India, Phone: +919452929750, e-mail: dr.harishchandratiwari@gmail.com
Date of received: 29 May 2016

Date of acceptance: 08 September 2016

Date of publication: October 2016

\section{INTRODUCTION}

All women who want to have babies want to do so safely, with reassurance and care throughout their pregnancies, during birth, and beyond. Yet, for many women childbearing is experienced not as a joyful event as it should be. Even today, perhaps, delivery is the commonest event where life and death stand side by side for both the expectant mother and her newborn.

Prevention of maternal deaths is one of our foremost goals to provide safety to motherhood and to avoid loss to the family, society, and the nation. This is the key objective of reproductive and child health program in India. In order to reduce maternal mortality and to promote institutional delivery, the government has launched incentive-based scheme named Janani Suraksha Yojana. ${ }^{1}$

India has made noticeable progress in curbing the maternal mortality rate from 560 in 1990 to 178 (Sample Registration System Special Bulletin, December 2013). ${ }^{2}$ However, as per the Millennium Development Goal (MDG) mandate, India needs to reduce its maternal mortality ratio (MMR) further down to 103. Despite the uniformity in program design throughout the country, there is a considerable regional variation in the pattern of maternal mortality. The situation is worse in states like Bihar, Uttar Pradesh, and certain belts of Rajasthan.

Maternal mortality ratio of Uttar Pradesh (258 Annual Health Survey 2012-2013) ${ }^{3}$ is still very high as compared to national average. Within the state of Uttar Pradesh, MMR of Gorakhpur Mandal (Maharajganj, Gorakhpur, Kushinagar, and Deoria) and Basti Mandal (Siddharth Nagar, Basti, and Sant Kabir Nagar) was 302 and 304 (Annual Health Survey 2012-13) ${ }^{3}$ respectively.

The explanations and answers to these regional variations are complex. This study was planned with the objectives to explore each and every maternal death that had occurred during the last 4 years with respect to profile of maternal death, time trend, geographical distribution, cause of death, delays in case of maternal deaths to find out reasons of high maternal mortality in Baba Raghav Das Medical College, the only tertiary care institute of this region. These determinants could be utilized in 


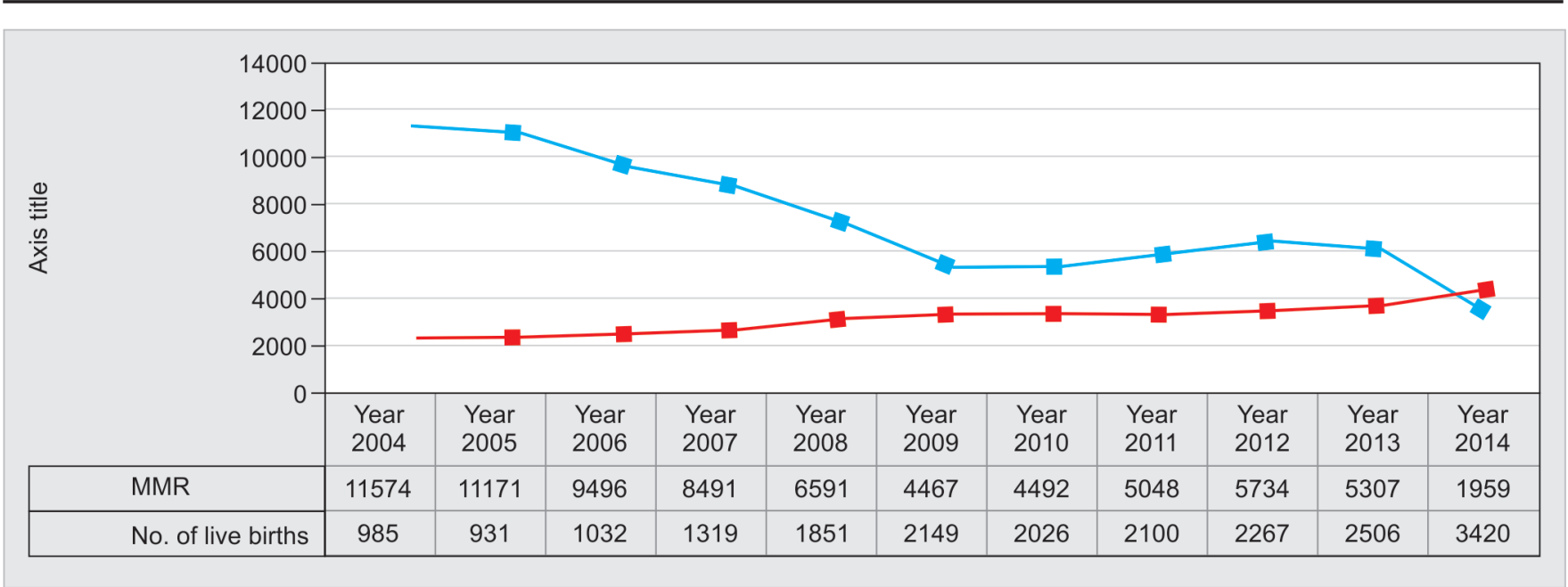

Graph 1: Trend of MMR (2004-2014)

assessing the probability of maternal death in each case and interventions accordingly.

\section{MATERIALS AND METHODS}

In this study, data were collected from records of all maternal deaths that had occurred in the Department of Obstetrics and Gynecology, Baba Raghav Das Medical College, Gorakhpur from March 2011 to December 2014. Records of all maternal deaths during this period were scrutinized for socio-demographic profile, obstetric history, antenatal care history, causes of maternal mortality, time trend, geographical or regional distribution, admission and death interval, condition of patients on admission, outcome of pregnancy, and reasons for delay. Records of number of maternal deaths and live births were also collected for previous 11 years (2004-2014).

Maternal death was defined and classified according to the World Health Organization's International Classification of Diseases (ICD), 10th revision (ICD-10). ${ }^{4}$ Direct deaths result from obstetric complications of pregnant state (pregnancy, labor, and puerperium).

Indirect deaths are those resulting from previously existing disease or disease that developed during pregnancy and aggravated by pregnancy. Deaths were classified as direct and indirect. Maternal mortality ratio is defined as the number of direct and indirect maternal deaths per 100,000 live births up to 42 days after the termination of pregnancy. Data were analyzed using Microsoft Office Excel 2007.

\section{RESULTS}

Maternal mortality ratio was 11,574 (a total of 114 maternal deaths out of 985 live births) during the year 2004 and showed a continuous declining trend during the successive years. Maternal mortality ratio has dropped almost six times during the last 11 years. During the year 2014 it was 2,847 (67 maternal deaths out of 3,420 live births)
(Graph 1). Number of deliveries at this institute increased almost three times during the same period.

Trend line of maternal mortality revealed a higher proportion of maternal deaths in the second half of every year and particularly during the months of July, August, September, and October (Graph 2).

\section{PROFILE OF MATERNAL DEATHS}

Out of the total maternal deaths, $61 \%$ majority belonged to 20 to 30 years age group, $18 \%$ belonged to $<20$ years age group, and $21 \%$ belonged to $>30$ years age group. Among the total maternal deaths, majority were Hindus $(86.7 \%)$ and the rest were Muslims (13.3\%).

Out of the total maternal deaths, $38 \%$ belonged to other backward class (OBC) category, 37.8\% belonged to scheduled caste (SC) category, and only $24.2 \%$ belonged to general category. Among the total maternal deaths, majority $(92.1 \%)$ were housewives and illiterates $(61.8 \%)$.

Among total maternal deaths, $72.6 \%$ majority were multigravidas and $27.4 \%$ were primigravidas.

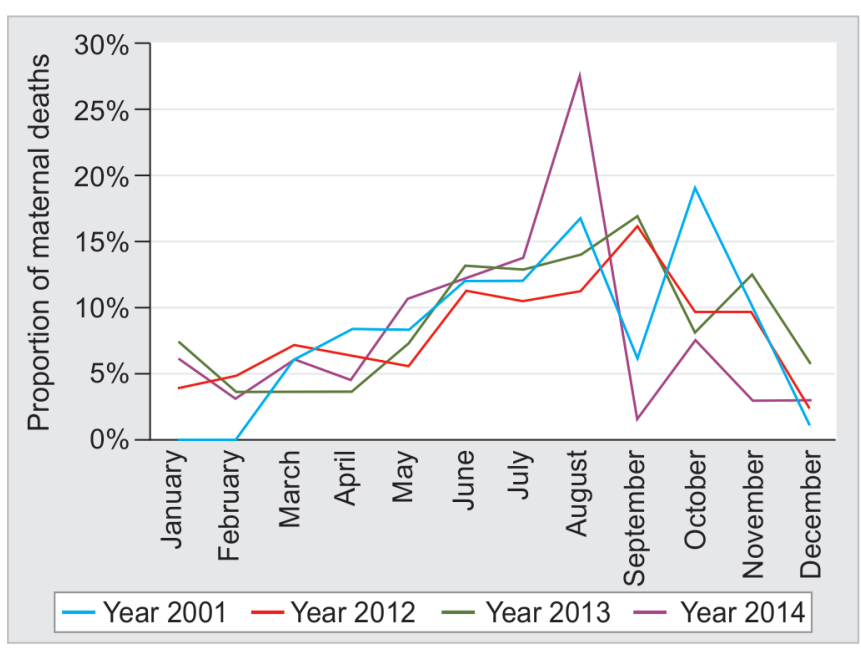

Graph 2: Month wise trend of proportion of maternal deaths in the last 4 years (March 2011-December 2014) 
Only $27.34 \%$ of women who died here had received antenatal care, while $72.66 \%$ of women did not receive any kind of antenatal care. Lack of awareness $(82.1 \%)$ was the most common reason behind it, while lack of accessibility $(6.4 \%)$ and lack of funds $(8.87 \%)$ were other reasons.

Eclampsia (24.88\%) was found to be the most common cause of maternal mortality. Postpartum hemorrhage was the next important cause of maternal deaths. Declining trend was observed in proportion of maternal deaths due to postpartum hemorrhage. Proportion of maternal deaths due to preeclampsia showed a continuous rise in the last 4 years. Anemia was responsible for $13.3 \%$ of the deaths. Ectopic pregnancy and abortions accounted to $3.8 \%$ of maternal deaths. Obstructed labor and sepsis accounted to 2.46 and $6.9 \%$ maternal deaths respectively. Associated medical conditions with pregnancy (14.29\%) were important indirect causes of maternal deaths (Table 1).

\section{Admission to Death Interval}

Admission to death interval analysis of the present study revealed that $30.2 \%$ of women died within 6 hours of admission, $16.7 \%$ within 6 to 12 hours of admission, $18.2 \%$ within 18 to 24 hours of admission, $13.6 \%$ within 24 to 48 hours, $9.8 \%$ within 48 to 72 hours, and $11.4 \%$ of women died after 72 hours of admission.

Majority $(73.4 \%)$ of maternal deaths had occurred during postpartum period, $14.3 \%$ during antenatal period, and $2.3 \%$ during intranatal period.

Delay in seeking care was the most common delay that was observed in the present study. Most important reason stated for this delay was unawareness of danger signs. During the year 2011, unawareness of danger signs was one of the causes of delay among $73 \%$ of maternal deaths and it declined to $52 \%$ in year 2014. Illiteracy and ignorance was observed as the second most important reason (31-36\%) for delay. Delay in getting transport and not reaching appropriate facility in time was found to be another important reason for delay during years 2011-2013 (40\%), but a sharp decline was observed during year $2014(20 \%)$ (Graph 3).

\section{DISCUSSION}

Although MMR had dropped six times in the last 11 years, still MMR at this institute was very high. Other Indian studies done in previous years have shown wide variation in MMR ranging from 3,344 per 100,000 live births ${ }^{5}$ to 1,650 per 100,000 live births. ${ }^{6}$ High MMR might be due to-being a tertiary referral center which deals with exclusively high-risk patients.

Almost three-quarters $(74.88 \%)$ of pregnant ladies who died here were referred from some other centers and belonged to neighboring district of Gorakhpur [Deoria (14.78\%), Kushinagar (14.78\%), and Maharajganj $(10.84 \%)]$.

The age distribution pattern of deceased mothers was similar to the pattern of maternal deaths in India, ${ }^{4}$ as most (61\%) of the deceased mothers were in 20-30 years age group. In a study by Sarin et al, ${ }^{7} 57.8 \%$ of maternal deaths were in the 21 to 30 years age group. However, proportional number of deliveries and near miss ${ }^{8}$ in age-specific groups has not been computed for this study.

Three-quarters of pregnant ladies who died here belonged to OBC and SC categories, while representation of these categories among general population is $<50 \%$ as per census 2011. Similar to present study, an Indian Council and Medical Research study ${ }^{9}$ reported that $62.7 \%$ of maternal deaths were of uneducated women. A study by Sarin et $\mathrm{al}^{7}$ reported that a majority of the maternal deaths were among women belonging to poor class (76.4\%). Oladapo et $\mathrm{al}^{10}$ reported that about one-third of

Table 1: Causes of maternal mortality

\begin{tabular}{lllllll}
\hline Cause of death & & 2011 & 2012 & 2013 & 2014 & Total \\
\hline & Obstructed labor (\%) & 4.82 & 2.44 & 0.74 & 3.08 & 2.46 \\
& Postpartum hemorrhage (\%) & 21.83 & 19.51 & 19.26 & 15.38 & 16.50 \\
& Abortion (\%) & 2.41 & 0.00 & 1.48 & 0.00 & 0.99 \\
& Ectopic pregnancy (\%) & 1.20 & 4.07 & 3.70 & 1.54 & 2.96 \\
& Vesicular mole (\%) & 1.20 & 0.81 & 0.00 & 0.00 & 0.49 \\
& Anemia (failure) (\%) & 3.61 & 15.45 & 19.26 & 9.23 & 13.30 \\
& Eclampsia (\%) & 19.45 & 28.46 & 26.67 & 29.23 & 24.88 \\
& Sepsis (\%) & 4.82 & 8.13 & 3.70 & 13.85 & 6.90 \\
& APH (\%) & 14.46 & 5.69 & 5.93 & 9.23 & 8.36 \\
& Inversion of uterus (\%) & 0.00 & 0.00 & 0.00 & 3.08 & 0.49 \\
& Postoperative complications (\%) & 1.20 & 1.63 & 0.00 & 1.54 & 0.99 \\
& Pulmonary embolism (\%) & 1.20 & 0.81 & 0.74 & 0.00 & 0.74 \\
& CVA (\%) & 0.00 & 4.88 & 0.74 & 1.54 & 1.97 \\
& Medical condition (\%) & 13.53 & 5.69 & 14.81 & 6.15 & 14.29 \\
& Diabetes (\%) & 1.20 & 0.81 & 0.00 & 1.54 & 0.74 \\
& Others (\%) & 9.64 & 1.63 & 2.22 & 4.62 & 3.94 \\
\hline
\end{tabular}




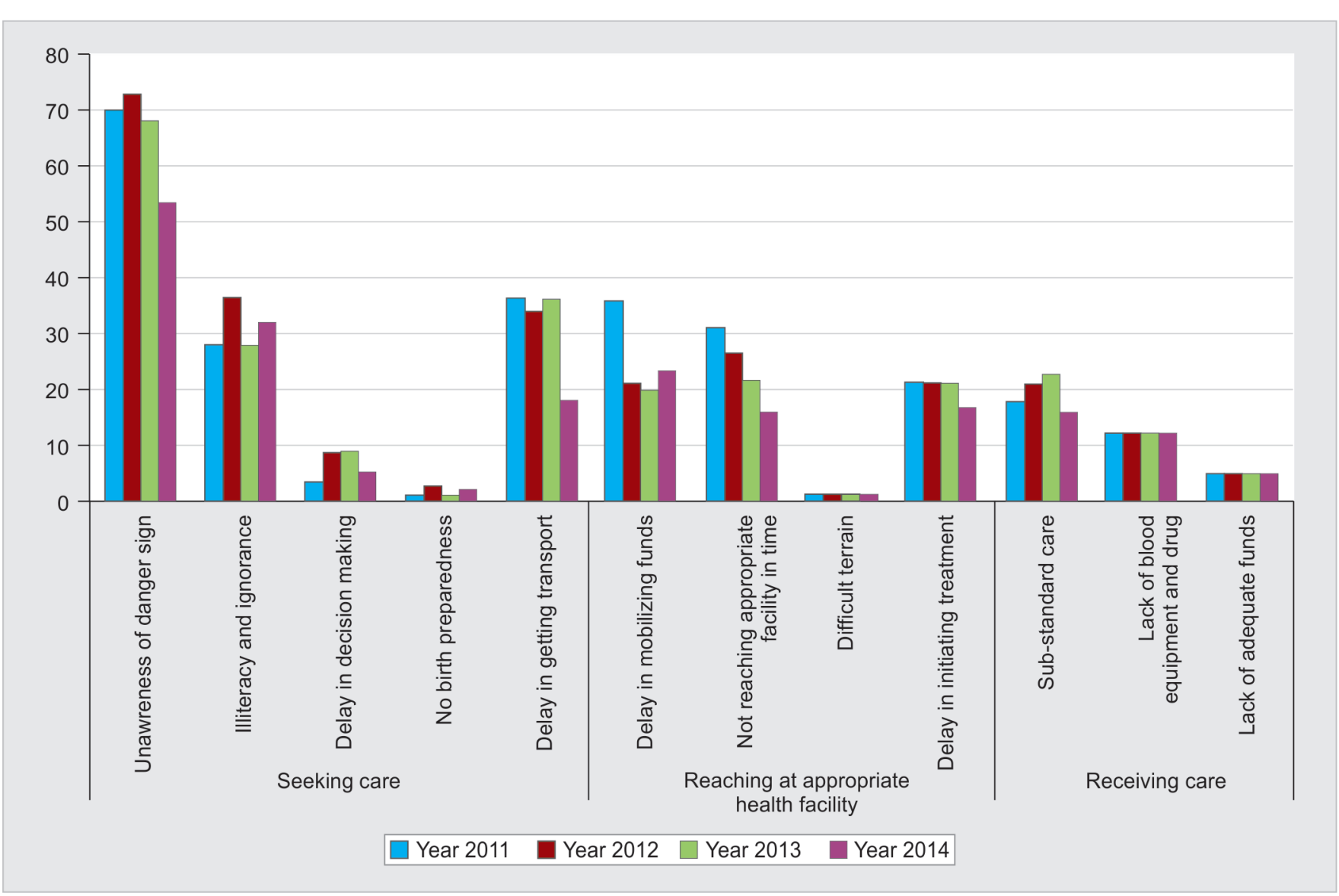

Graph 3: Type of delays contributing to maternal deaths (multiple delays were present simultaneously)

the women who died were experiencing their first child birth (similar to our present study). Early age at marriage, illiteracy, poor socioeconomic status, and multiparity are some of the determinants of maternal mortality and can act as risk factors. ${ }^{11}$

Proper antenatal care checkup, tetanus toxoid immunization, and iron-folic acid tablet consumption are essential obstetric care to make better outcome of childbirth. A majority of the mothers who died had not received any kind of antenatal care. Lack of awareness was found to be the most common reason for it. Promotion for antenatal care and institutional delivery are the prime responsibilities of ASHA.

Admission to death interval analysis of present study revealed that $30.22 \%$ of women died within 6 hours of admission, as most of the patients were in moribund and comatose conditions. These patients were brought late to this institute and irreversible damage had already occurred.

In the present study, eclampsia was found to be the most common cause of maternal mortality followed by postpartum hemorrhage, which can be compared with the study by Paul et $\mathrm{al}^{12}$ who reported hypertensive disorders of pregnancy (30\%) as the most common cause of maternal deaths and Oladapo et $\mathrm{al}^{10}$ who reported hypertensive disorders of pregnancy $(28 \%)$ to be the most common cause of maternal deaths followed by hemorrhage $(21.3 \%)$, whereas Government of India and $\mathrm{WHO}^{13}$ reported hemorrhage as the most common cause. This clearly shows that the pattern of causes in medical institutes is quite different from that seen in community.

Direct causes contributed to $78.32 \%$ of all deaths in the present study. In most of the hospital-based studies in India, ${ }^{12,14-16}$ the direct causes were responsible for 51 to $82 \%$ of maternal mortalities.

Delay in seeking care was found to be a major contributing factor for most of maternal deaths. Most important reason stated for this delay was unawareness of danger signs. During the year 2011, unawareness about danger signs as a reason for delay was reported in $73 \%$ of maternal deaths and it reduced to $52 \%$ in the year 2014. Illiteracy and ignorance was observed as the second most important reason (31-36\%) for delay. Delay in getting transport and not reaching to an appropriate health facility showed a sharp decline in the year 2014 (20\%) as compared to years 2011-2013 (40\%). In a study by Cham et al, ${ }^{17} 7$ of the 32 cases studied were delayed in the process of seeking medical attention and 27 of the 32 women were delayed in the process of reaching an appropriate medical facility. Few of the women experienced delay in receiving prompt and adequate obstetric care at the hospital level. 


\section{CONCLUSION}

Maternal mortality ratio dropped almost six times in the last 11 years. Early age at marriage, illiteracy, poor socioeconomic status, and multiparity were found to be important determinants of maternal mortality and can act as risk factors. The pattern of causes of maternal deaths in this institute (preeclampsia) is different from that found in the community (postpartum hemorrhage). Delay in seeking care because of unawareness and illiteracy and ignorance was found to be the major contributing factor for most of maternal deaths.

\section{REFERENCES}

1. Janani Suraksha Yojana. Guidelines for implementation. New Delhi: Government of India, Ministry of Health and Family Welfare; 2005. p. 1-29.

2. Special Bulletin on Maternal Mortality in India 2010-12 [last cited 2015 Feb 10]. Available from: http:/ / www.censusindia. gov.in/vital_statistics/SRS_Bulletins/MMR_Bulletin_201012 pdf.

3. Annual Health Survey 2012-13. Fact sheet [last cited 2015 Feb 25]. Available from: http://www.censusindia.gov.in/ vital_statistics / AHSBulletins / AHS_Factsheets_2012-13/ FACTSHEET-UTTAR_PRADESH.pdf.

4. Government of India (Sample Registration System). Maternal Mortality in India: 1997-2003, trends, causes and risk factors, Registrar General, India, New Delhi in collaboration with Centre for Global Health Research, Toronto, ON, Canada.

5. Poonam AY, SarojS, Richa S, Urvashi V, KaushalSK, HarpreetC. Impact of JSY on Institutional delivery \& MMR in a tertiary care centre in Western U.P. J Obstet Gynecol 2013;(19):29-30.
6. Sharma S. A study of maternal mortality in a rural medical college hospital. J Obstet Gynecol India 1994:44:548-551.

7. Sarin AR, Singla P, Kaur H. Maternal mortality - aetiological factors: analytic study from a teaching hospital of Punjab. Indian J Mat Child Health 1992 Jul-Sep;3(3):69-73.

8. World Health Organization. Beyond the numbers: reviewing maternal deaths and complications to make pregnancy safer. Geneva: World Health Organization; 2004.

9. Bedi N, Kambo I, Dhillon BS, Saxena BN, Singh P. Maternal deaths in India: preventable tragedies (An ICMR Task Force Study). J Obstet Gynecol India 2001;51:86-92.

10. Oladapo OT, Lamina MA, Fakoya TA. Maternal deaths in Sagamu in the new millennium: a facility-based retrospective analysis. BMC Pregnancy Childbirth India 2006 Mar 10;6:6.

11. Konar H. DC Dutta's Textbook of obstetrics. 7th ed. New Delhi: Jaypee Brothers Medical Publishers; 2011. p. 603-4, 630-1.

12. Paul B, Mohapatra B, Kar K. Maternal deaths in a tertiary health care centre of Odisha: an in-depth study supplemented by verbal autopsy. Indian J Community Med 2011 Jul-Sep; 36(3):213-216.

13. WHO, UNICEF, UNFPA. Maternal mortality in 2004, estimates developed by WHO. Geneva: UNICEF and UNFPA; 2004.

14. Rao KB. Maternal mortality in a teaching hospital in Southern India: a 13-year study. Obstet Gynecol 1975 Oct;46(4): 397-400.

15. Majhi AK, Sanyal P, Chakraborty T, Mukherjee GG. Changing trends in maternal mortality in a teaching cum referral hospital. J Obstet Gynaecol India 1996 Jun;46(3): 345-353.

16. Rao KB, Malika PE. A study of maternal mortality in Madras city. J Obstet Gynaecol India 1977 Dec;27(6):876-880.

17. Cham M, Sundby J, Vangen S. Maternal mortality in the rural Gambia: a qualitative study on access to emergency obstetric care. Reprod Health 2005;2:3. 